Goldschmidt 2021 Abstract

https://doi.org/10.7185/gold2021.4770

\section{How far back? Testing plate tectonics as the null hypothesis}

\section{MICHAEL BROWN ${ }^{1}$ AND TIM JOHNSON ${ }^{2}$}

${ }^{1}$ University of Maryland

${ }^{2}$ Curtin University

Presenting Author: mbrown@umd.edu

We test plate tectonics (PT) as the null hypothesis of tectonic mode on Earth back through the Precambrian. In the Phanerozoic, orogenesis imprints a distinctive metamorphic pattern that is accepted as a manifestation of PT. Thus, secular change of metamorphism offers clues about both the style and emergence of PT in the Precambrian [1]. Using a dataset of peak pressure $(P)$ and temperature $(T)$ values (Figure), metamorphism is classified into three types using thermobaric ratio $(T / P)$, which varies spatially and temporally in orogens. Each type of metamorphism is associated with a specific tectonic settingfrom low to high T/P (Figure): subduction, orogen and orogenic hinterland. Orogens younger than Archean record bimodal metamorphism [2], comprising belts with lower and higher $T / P$ (Figure), corresponding to the subduction suture and associated orogen, and a region of extension in the orogenic hinterland, respectively. Thus, a strong case can be made for PT back to the early Paleoproterozoic, when fragmentation of supercratons led to amalgamation of the resulting pieces in the supercontinent Columbia, where suturing orogens preserve seismic evidence consistent with subduction. Overall, significant changes in the crustal record of metamorphism since the Mesoarchean, confirmed by sequential (cumulative sum) analysis of $T / P$ for the dataset as a whole, suggest three geodynamic cycles: a transition to PT that was completed by the early Paleoproterozoic; a Proterozoic style of orogenesis, characterized by the prevalence of hot, thin and low orogens, lasting until the breakup of Rodinia; and, modern PT. During the Archean, initiation of subduction could have occurred on multiple occasions at various locations creating conflicting signals in the geological record. However, localized discontinuous evidence of unstable subduction does not identify a global PT mode. Based on the main controls on variations in plate velocities, the emergence and development of PT across the globe could have been related to the rise of the continents and the accumulation of sediments at continental edges, and subsequently in trenches, to lubricate and stabilize subduction [3].

[1] Brown, Johnson \& Gardiner (2020) AREPS 48, 12.112.30 .

[2] Holder et al. (2019) Nature 572, 378-381.

[3] Sobolev \& Brown (2019) Nature 570, 52-57.
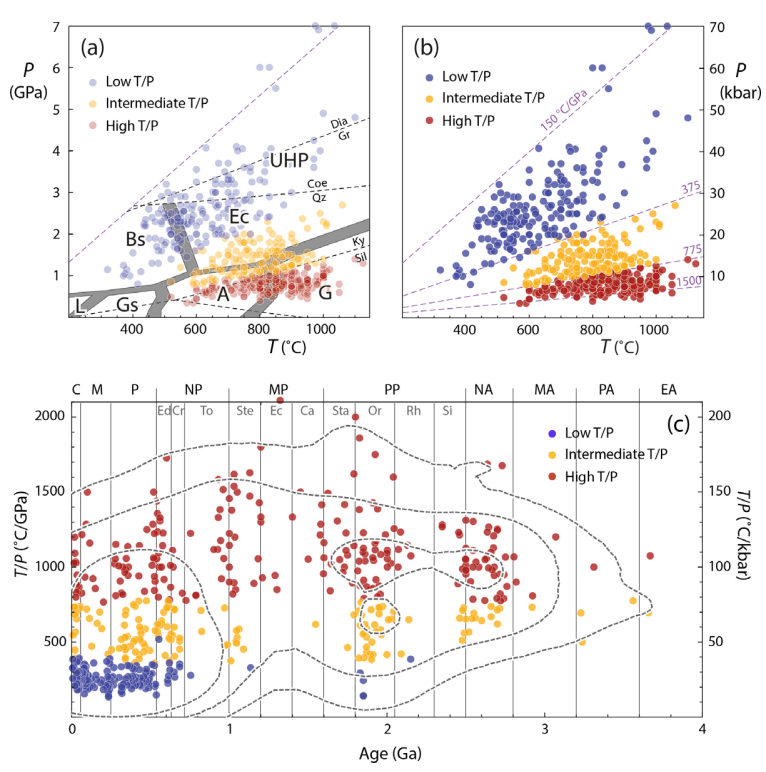